\title{
Case Report: Behçet's disease accompanied with vitiligo
}

\section{[version 1; peer review: 2 approved]}

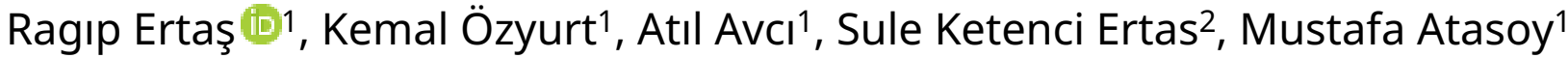

1Dermatology Department, Kayseri Training and Research Hospital, Kayseri, 38050, Turkey

${ }^{2}$ Department of Rheumatology, Erciyes University Faculty of Medicine, Kayseri, 38039, Turkey

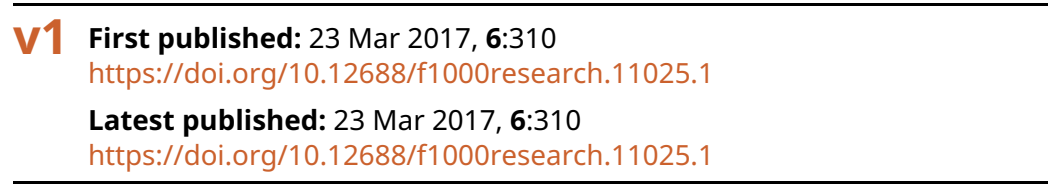

\section{Abstract}

Recently, a few case reports and clinical studies have been published that explore the association of Behçet's Disease (BD) and vitiligo, with conflicting results. Genetic and immunological properties of BD and presence of autoantibodies support autoimmunity, but clinical features suggest autoinflammatory diseases. BD is thought to be a cornerstone between autoimmune and autoinflammatory diseases. On the other hand, vitiligo has been accepted as an autoimmune disease with associations of other autoimmune disorders and there is a possible role of autoimmunity in pathogenesis of the disease. Significant advances have been made understanding the pathogenesis and genetics of $\mathrm{BD}$. However, it is worth presenting rare clinical variants for improving the clinical understanding of BD. Herein, we are presenting a case with diagnosis of both Behçet's disease and vitiligo in same patient, which is a rare occurrence. Discussion and demonstrating the association of these two diseases may give rise to understanding similar and different aspects of autoimmunity and autoinflammatory pathogenesis of both diseases.

\section{Keywords}

Behçet's Disease, Vitiligo, Autoimmunity, Autoinflammatory, Depigmentation, Erythema nodosum, Thrombophlebitis, Arthritis

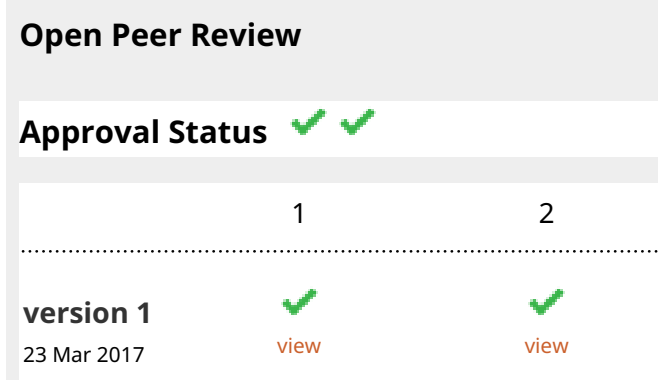

1. Zafer Türkoğlu, Istanbul Medeniyet University, Istanbul, Turkey

2. Rasheedunnisa Begum (iD), Maharaja

Sayajirao University of Baroda, Vadodara, India

Any reports and responses or comments on the article can be found at the end of the article.

Corresponding author: Ragıp Ertaş (ragipertas@gmail.com)

Competing interests: No competing interests were disclosed.

Grant information: The author(s) declared that no grants were involved in supporting this work.

Copyright: $\odot 2017$ Ertaş R et al. This is an open access article distributed under the terms of the Creative Commons Attribution License, which permits unrestricted use, distribution, and reproduction in any medium, provided the original work is properly cited. Data associated with the article are available under the terms of the Creative Commons Zero "No rights reserved" data waiver (CC0 1.0 Public domain dedication).

How to cite this article: Ertaş R, Özyurt K, Avcı A et al. Case Report: Behçet's disease accompanied with vitiligo [version 1; peer review: 2 approved] F1000Research 2017, 6:310 https://doi.org/10.12688/f1000research.11025.1

First published: 23 Mar 2017, 6:310 https://doi.org/10.12688/f1000research.11025.1 


\section{Introduction}

Behçet's disease (BD) is a systemic disease with an unknown origin characterized by recurrent oral ulcers, mucocutaneus disorders and ocular findings. BD may be life-threatening, affecting the central nervous system, large vessels and the gastrointestinal tract ${ }^{1}$. Numerous studies have investigated the etiopathogenesis of BD over a long period, but the etiology and mechanisms of pathogenesis have not yet been fully explained ${ }^{2}$.

Vitiligo is a chronic depigmenting disorder representing white patches in the skin or hair extinct of functional melanocytes ${ }^{3}$. Autoimmunity has been implicated in the pathogenesis of the disease, and associations with autoimmune diseases have been demonstrated ${ }^{4}$.

Here, we present a unique case of $\mathrm{BD}$ and vitiligo in the same patient. This is a very rare condition and gives the opportunity to understand similar and different aspects of autoimmunity and autoinflammatory pathogenesis of both diseases by observing clinical and laboratory findings.

\section{Case report}

A 24-year-old woman was admitted to the Clinic of Dermatology at the Kayseri Training and Research Hospital. The patient complained of swelling and pain in her legs for two weeks. Medical history of the patient included monthly relapsing oral aphthous ulcers for three years, and one attack of thrombophlebitis and arthritis previously. She had received treatment in various clinics and times for relapsing oral aphthous ulcers, including colchicum tablets, mouthwashes, corticosteroid and antibiotic creams. For thrombophlebitis and arthritis she was hospitalized and given therapy. The patient had vitiligo for 14 years. Her relatives had neither BD nor vitiligo.

A physical examination revealed erythema nodosum-like eruptions on the patient's legs, and white, depigmented patches on the patient's bilateral lateral malleolus, wrists, eyelids, knees, fingers and an oral aphthous ulcer on the lower lip mucosa (Figure 1Figure 4). An ophthalmological examination resulted in

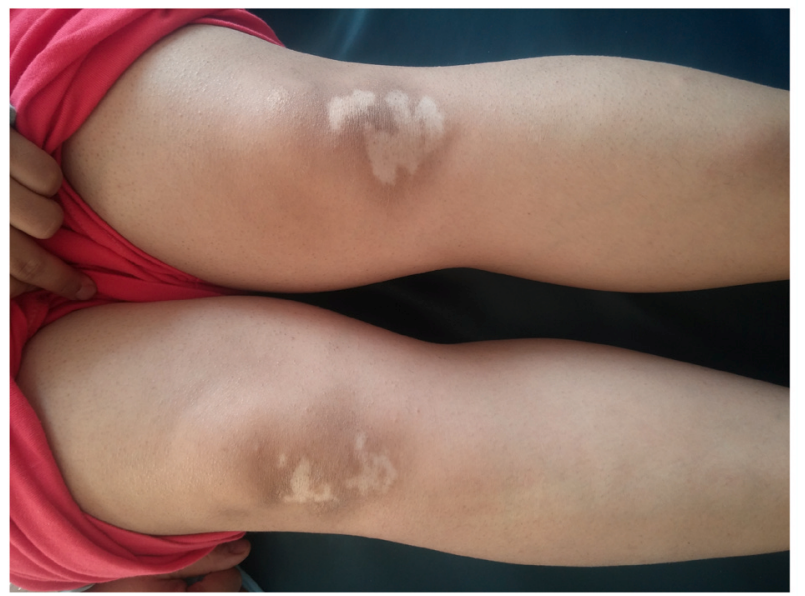

Figure 1. Depigmented patches on the bilateral knees. normal findings even though the patient had pain in her eyes. A pathergy test was negative. Laboratory examination showed hemoglobin,10.8 gr/dL(reference level,12-16gr/dL);platelet count,285 10^3/uL(130-400 10^3/uL); white cell count,635 10^3/uL (46-10210^3/uL);serum folic acid,4.84 ng/ml(3.1-17.54ng/ $\mathrm{ml}$ ); serum ferritin, $8.5 \mathrm{ng} / \mathrm{ml}$ (110-305ng/ml);vitamin B12, 217 $\mathrm{pg} / \mathrm{ml}(126-505 \mathrm{pg} / \mathrm{ml}) ;$ serum iron, $28 \mathrm{ug} / \mathrm{dL}$ (60-180ug/dL);serum total iron binding capacity, $345 \mathrm{ug} / \mathrm{dL}(155-355 \mathrm{ug} / \mathrm{dL})$; C-reactive protein,5.11 $\mathrm{mg} / \mathrm{L} \quad(0-5 \mathrm{mg} / \mathrm{L})$; erythrocyte sedimentation rate, $22 \mathrm{~mm} / \mathrm{h} \quad(0-20 \mathrm{~mm} / \mathrm{h})$;rheumatoid factor, $10.2 \mathrm{IU} / \mathrm{ml}$ (0-15IU/ml);serum antistreptolysin-o titer,174IU/ml (0-200IU/ $\mathrm{ml})$; free $\mathrm{T} 3,3.68 \mathrm{pg} / \mathrm{ml}$ (2.5-3.9); free $\mathrm{T} 4,0.75 \mathrm{ng} / \mathrm{dl}(0.54-1.24$ $\mathrm{ng} / \mathrm{dl})$; thyroid stimulating hormone, $1.56 \mathrm{mIU} / \mathrm{L}(0.4-5.6 \mathrm{mIU} / \mathrm{L})$; antithyroglobulin antibody test, $<2.2 \mathrm{IU} / \mathrm{ml}(0-4 \mathrm{IU} / \mathrm{ml})$; antithyroid peroxidase antibody test, $0.6 \mathrm{IU} / \mathrm{ml}(0-9 \mathrm{IU} / \mathrm{ml})$.

A diagnosis of $\mathrm{BD}$ was made according to the International Criteria for Behçets Disease (ICBD $)^{5}$ and vitiligo was diagnosed based

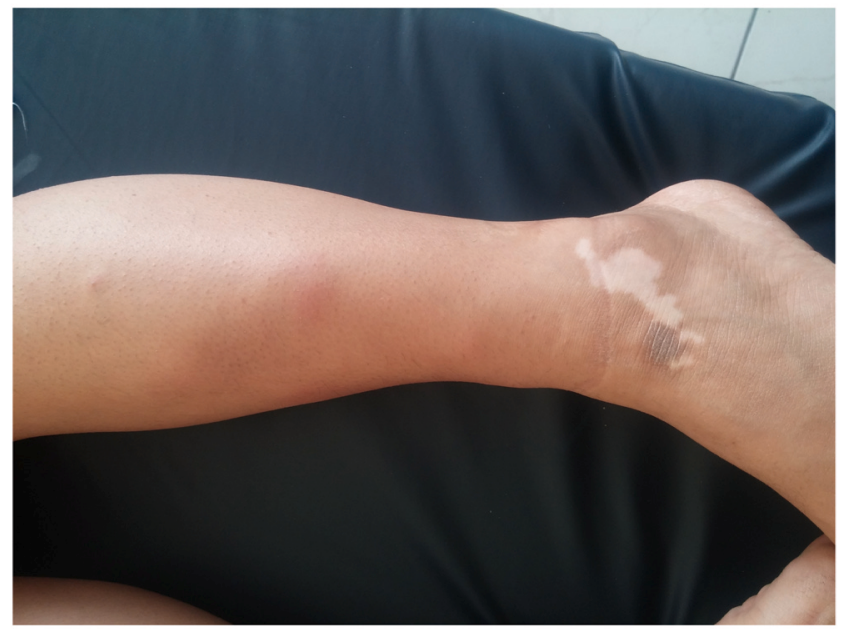

Figure 2. Erythema nodosum-like eruptions and depigmented patches on the lateral malleolus.

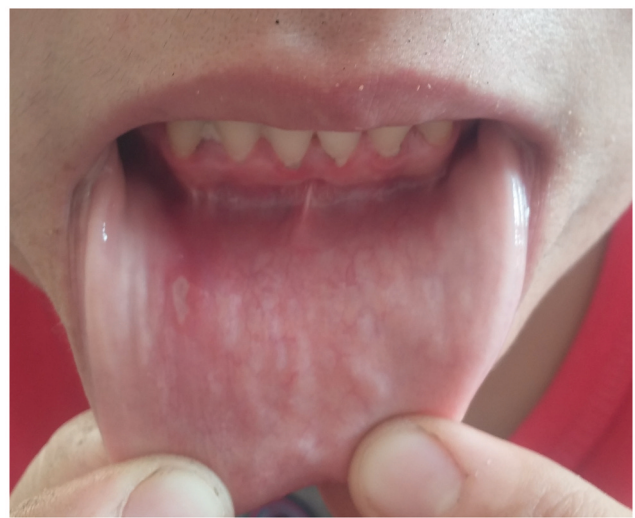

Figure 3. An aphthous ulcer on the lower lip mucosa. 


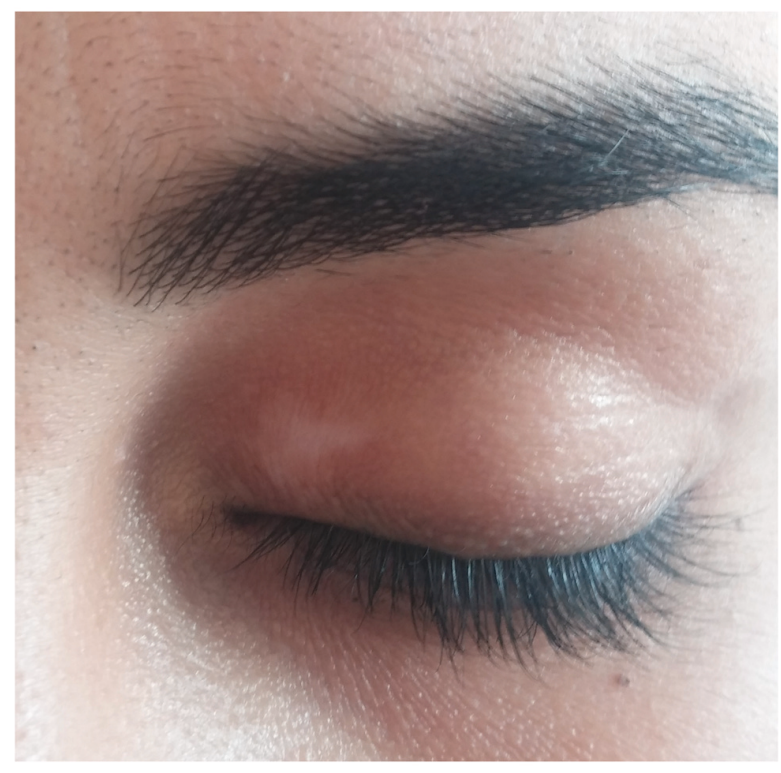

Figure 4. A depigmented patch on the upper eyelid.

on prior physical examination. Diagnosis of $\mathrm{BD}$, according to the ICBD, was based on only clinical features, but not any laboratory finding. For the ICBD, ocular lesions, oral aphthosis and genital aphthosis are each assigned 2 points, while skin lesions, central nervous system involvement and vascular manifestations are assigned 1 point each. The pathergy test was assigned 1 point. A patient scoring 4 points is classified as having BD. Our patient had 5 points: 2 for oral aphthosis, 1 for erythema nodosum and 1 for thrombophlebitis. Additionally, laboratory results mentioned above showed an iron deficiency anemia.

\section{Follow-up and outcomes}

The patient was hospitalized and treated in our dermatology clinic for 10 days. She was given systemic corticosteroid and wet dressing for erythema nodosum-like eruptions on her legs. These lesions improved and she was discharged at the end of 10 days. She was not living in borders of our province and was recommended for follow-up in a local dermatology clinic.

\section{Discussion}

Clinical and immunological understandings of the disease suggest $\mathrm{BD}$ is a cornerstone between autoimmune and inflammatory disease. Clinical features and male predominance suggest inflammatory diseases; however, sharing class I MHC association in genetic details and presence of autoantibodies in patients supports autoimmunity ${ }^{2}$. Clinical characteristics and symptoms are the main factors for diagnosing $\mathrm{BD}$, but a specific diagnostic feature or laboratory method is not yet available. The clinical features of patients in countries with a high prevalence of BD may help to clarify the pathogenesis of $\mathrm{BD}^{1}$. Here we present a case of $\mathrm{BD}$ accompanied by vitiligo. Vitiligo is a common skin disorder and various factors participate in the etiopathogenesis, which causes autoimmune melanocytic destruction. Autoimmune thyroid diseases and pernicious anemia are frequently associated with vitiligo ${ }^{3,4}$. Recently, a few case reports and clinical studies have been published that demonstrate the association of BD with vitiligo, with conflicting results. Oran et al. showed that the frequency of vitiligo was not increased among patients with $\mathrm{BD}^{6}$, while two different reports mentioned the coexistence of vitiligo and $\mathrm{BD}^{7,8}$. In addition, Guney et al. claimed that vitiligo occurred during interferon therapy in a patient with $\mathrm{BD}^{9}$.

Vogt-Koyanagi-Harada (VKH) syndrome is an inflammatory disorder characterized by bilateral panuveitis, and is frequently associated with poliosis, vitiligo, alopecia, central nervous system and auditory symptoms ${ }^{10}$. VKH syndrome is not often mistaken as BD. However, VKH syndrome has similar properties to BD and the etiology of both diseases remains unknown; however, an autoimmune response has been presumed to be implicated in their pathogenesis. Hu et al. mentioned TT genotype of rs7574865 in STAT4 gene may be a susceptible factor for VKH syndrome in a Chinese Han population, and GG genotype of this SNP may confer susceptibility in male BD patients ${ }^{11}$. Our patient had only vitiligo and no other symptoms of VKH syndrome.

These case reports and studies give rise to thought about the association of BD and vitiligo. In our case, vitiligo had been present for 14 years before the diagnosis of BD. Antithyroid autoantibodies are not included in the diagnosis of $\mathrm{BD}$, but show evidence of autoimmunity. These were negative in our patient. We don't know whether a unique genetic predisposition or any environmental or infectious factor caused this status. Interestingly, Karincaoglu et al. declared incidental coexistence of $\mathrm{BD}$ and vitiligo and also koebnerization of genital ulceration of $\mathrm{BD}^{7}$. However, in their case, the patient had vitiligo patches not only in the scar area of genital region, but also on other body surfaces.

Vitiligo may be only one symptom of a big picture, as in $\mathrm{VKH}$ syndrome $^{12}$. A different disease may have the features of BD and vitiligo. Indeed, all these implications are speculative and we need new studies and cases. We present a case of BD accompanied with vitiligo, a rare clinical variant of $\mathrm{BD}$, which may help to improve the clinical understanding of BD.

\section{Consent}

Written informed consent was obtained from the patient for the publication of the manuscript.

\section{Author contributions}

RE: wrote the manuscript; KO, AA and MA: Helped manage the patient's diagnosis and therapy, and prepared the manuscript; SKE: patient's consultant from the Department of Rheumatology.

\section{Competing interests}

No competing interests were disclosed.

\section{Grant information}

The author(s) declared that no grants were involved in supporting this work. 
1. Ozyurt K, Colgecen E, Baykan H: Does familial occurrence or family history of recurrent oral ulcers influence clinical characteristics of Behçet's disease? Acta Dermatovenerol Croat. 2013; 21(3): 168-73. PubMed Abstract

2. Pineton de Chambrun $M$, Wechsler $B$, Geri G: New insights into the pathogenesis of Behçet's disease. Autoimmun Rev. 2012; 11(10): 687-98. PubMed Abstract | Publisher Full Text

3. Kovacs SO: Vitiligo. J Am Acad Dermatol. 1998; 38(5 Pt 1): 647-66; quiz 667-8. Review.

PubMed Abstract | Publisher Full Text

4. Kemp EH, Waterman EA, Weetman AP: Autoimmune aspects of vitiligo. Autoimmunity. 2001; 34(1): 65-77. PubMed Abstract | Publisher Full Tex

5. International Team for the Revision of the International Criteria for Behçet's Disease (ITR-ICBD), The International Criteria for Behçet's Disease (ICBD): a collaborative study of 27 countries on the sensitivity and specificity of the new criteria. J Eur Acad Dermatol Venereol. 2014; 28(3) 338-347.

PubMed Abstract | Publisher Full Text

6. Oran M, Hatemi G, Tasli L, et al.: Behçet's syndrome is not associated with vitiligo. Clin Exp Rheumatol. 2008; 26(4 Suppl 50): S107-9.

PubMed Abstract

7. Borlu M, Cölgeçen E, Evereklioglu C: Behçet's disease and vitiligo in two brothers: coincidence or association? Clin Exp Dermatol. 2009; 34(8): e653-5. PubMed Abstract | Publisher Full Text

8. Karincaoglu Y, Kalayci B, Tepe B: Vitiligo koebnerized by behçet disease genital ulceration. Am J Clin Dermatol. 2009; 10(4): 268-70.

PubMed Abstract | Publisher Full Text

9. Guney E, Akcali G, Akcay BI, et al.: Vitiligo in a Patient Treated with Interferon Alpha-2a for Behçet's Disease. Case Rep Med. 2012; 2012: 387140.

PubMed Abstract | Publisher Full Text | Free Full Text

10. Norose K, Yano A: Melanoma specific Th1 cytotoxic T lymphocyte lines in Vogt-Koyanagi-Harada disease. Br J Ophthalmol. 1996; 80(11): 1002-8. PubMed Abstract | Publisher Full Text | Free Full Text

11. Hu K, Yang P, Jiang Z, Hou S, et al:: STAT4 polymorphism in a Chinese Han population with Vogt-Koyanagi-Harada syndrome and Behçet's disease. Hum Immunol. 2010; 71(7): 723-6.

PubMed Abstract | Publisher Full Text

12. Aktas E, Ertas R: Vitiligo'nun Tanı ve Ayırıcı Tanısı. Turkiye Klinikleri Journal of Dermatology Special Topics. 2009; 2: 23-6.

Reference Source 


\section{Open Peer Review}

\section{Current Peer Review Status:}

\section{Version 1}

Reviewer Report 05 May 2017

https://doi.org/10.5256/f1000research.11892.r22530

(c) 2017 Begum R. This is an open access peer review report distributed under the terms of the Creative Commons Attribution License, which permits unrestricted use, distribution, and reproduction in any medium, provided the original work is properly cited.

\section{Rasheedunnisa Begum}

Department of Biochemistry, Faculty of Science, Maharaja Sayajirao University of Baroda, Vadodara, Gujurat, India

1. Authors should mention the onset of vitiligo and Behçet's disease (BD) in clinical history. Moreover, it would be interesting if authors can mention the prevalence of vitiligo and BD for better correlation of the present study.

2. Vitiligo is a disorder without any gender biasness, as the subject recruited for the present study is a female it would add impact to the present study if authors should discuss the gender biasness for BD and discuss the same.

3. Authors should clearly state if depigmentation is due to vitiligo as there are many other depigmentation disorder. Was there any confirmation under wood's lamp for the same?

4. In the discussion section authors have mentioned association of vitiligo with other autoimmune disorders, for the same they should cite recent reports with higher sample size (for e.g. autoimmunity in onset and progression of vitiligo where atypical autoimmune disorder Thyroid has been discussed and many more).

5. Authors should also mention the extent of depigmentation, type and the activity of vitiligo in the patient as per standard classification guidelines.

6. The findings of laboratory examination along with the normal range can be represented in a tabular form to make it clearer.

7. Authors should also mention whether Koebner phenomenon was observed in the patient or not and discuss the same.

8. Authors should also mention whether approval from respective ethics committee was obtained for publishing the case study. 
Is the background of the case's history and progression described in sufficient detail? Yes

Are enough details provided of any physical examination and diagnostic tests, treatment given and outcomes?

Yes

Is sufficient discussion included of the importance of the findings and their relevance to future understanding of disease processes, diagnosis or treatment?

Partly

Is the case presented with sufficient detail to be useful for other practitioners?

Yes

Competing Interests: No competing interests were disclosed.

I confirm that I have read this submission and believe that I have an appropriate level of expertise to confirm that it is of an acceptable scientific standard.

Reviewer Report 18 April 2017

https://doi.org/10.5256/f1000research.11892.r21204

(C) 2017 Türkoğlu Z. This is an open access peer review report distributed under the terms of the Creative Commons Attribution License, which permits unrestricted use, distribution, and reproduction in any medium, provided the original work is properly cited.

\section{Zafer Türkoğlu}

Department of Dermatology, School of Medicine, Goztepe Training and Research Hospital, Istanbul Medeniyet University, Istanbul, Turkey

The case report that is being reported has been carried out well with no flaws in the design or methodology.

The case report was reported correctly, with acknowledgement of the existing body of work.

The work provides sufficient details for it to be useful for other practitioners.

It is suitable for indexing.

Is the background of the case's history and progression described in sufficient detail? Yes

Are enough details provided of any physical examination and diagnostic tests, treatment given and outcomes? 
Yes

Is sufficient discussion included of the importance of the findings and their relevance to future understanding of disease processes, diagnosis or treatment?

Yes

Is the case presented with sufficient detail to be useful for other practitioners?

Yes

Competing Interests: No competing interests were disclosed.

I confirm that I have read this submission and believe that I have an appropriate level of expertise to confirm that it is of an acceptable scientific standard.

The benefits of publishing with F1000Research:

- Your article is published within days, with no editorial bias

- You can publish traditional articles, null/negative results, case reports, data notes and more

- The peer review process is transparent and collaborative

- Your article is indexed in PubMed after passing peer review

- Dedicated customer support at every stage

For pre-submission enquiries, contact research@f1000.com 